\title{
O sermão expositivo religioso enquanto gênero do discurso: uma abordagem linguístico-dialógico-discursiva
}

\author{
The religious expository sermon as discourse genre: a \\ linguistic-dialogical-discursive perspective
}

\author{
Wilder Kleber Fernandes de Santana* \\ Universidade Federal da Paraíba \\ João Pessoa, Paraíba, Bahia, Brasil
}

\begin{abstract}
Resumo: O presente artigo se propõe a delimitar como objeto de estudo o gênero sermão expositivo em sua densidade enunciativa e discursiva adstritas ao discurso religioso. Objetiva compreender como os enunciados estão vinculados à apresentação de uma nova possibilidade de perspectiva autoral, ao observar como esta se concretiza em situações sociocomunicativas orais do uso da língua, como é o caso do gênero exposição oral. A base teórica consiste na perspectiva da abordagem da Análise Dialógica do Discurso, formulada por Bakhtin e o Círculo, assim como seus interlocutores no cenário das pesquisas desenvolvidas no Brasil e que se propaga na produção dos grupos de pesquisadores brasileiros, dentre eles, Francelino, Santana e Fiorin assim como a partir de propostas feitas por Lachler e Silva quanto ao discurso religioso. A metodologia se concentra na proposta da exposição oral do sujeito enquanto autor e responsável pelo seu discurso enunciativo, na constituição das suas enunciações por meio da interação (a partir dos discursos do outro). Assim demonstra-se a importância de se trabalhar com o Sermão enquanto gênero discursivo a partir de um sujeito responsivo ativo, quando este considera e valora os discursos de outrem.
\end{abstract}

Palavras-chave: Sermão expositivo. Discurso. Sujeito.

\begin{abstract}
The present article proposes to delimit as object of study the expositive sermon genre in its enunciative and discursive density attached to the religious discourse. It aims to understand how the statements are linked to the presentation of a new possibility of authorial perspective, when observing how it is established establishes in oral socio-communicative situations of the use of the language, as is the case of the oral exposition genre. The theoretical basis is the perspective of the Dialectical Analysis of Discourse approach formulated by Bakhtin and the Circle, as well as its interlocutors in the research scenario developed in Brazil and that is propagated in the production of Brazilian research groups, among them Francelino, Santana and Fiorin as well as from proposals made by Lachler and Silva regarding religious discourse. The methodology focuses on the proposal of the oral exposition of the subject as author and responsible for his enunciative discourse, in the constitution of his enunciations through interaction (from the discourses of the other). Thus it is demonstrated the importance of working with the Sermon as a discursive genre from an active responsive subject, when he considers and values the speeches of others.
\end{abstract}

Keywords: Expositive sermon. Speech. Subject.

* Doutorando e Mestre em Linguística pelo Programa de Pós-graduação em Linguística (PROLING) da Universidade Federal da Paraíba (UFPB). Mestre e Bacharel em Teologia (Faculdade Teológica Nacional, 2016); Mestrando em Arqueologia Bíblica (Faculdade Teológica Nacional, 2017) e Especialista em Gestão da Educação Municipal (UFPB, 2017). E-mail: wildersantana92@gmail.com. 


\section{INTRODUÇÃO}

Um dos princípios de base do pensamento bakhtiniano é o de que a linguagem é uma atividade que tem sua situação histórica e social concreta no momento da atualização dos enunciados, sendo essencialmente heterogênea. Além disso, essa concepção de linguagem é centrada nos interlocutores, apresentando, dessa forma, seu caráter ativo no ato verbal em que o discurso é produzido.

Posto que o "enunciado se forma entre dois indivíduos socialmente organizados" (VOLOCHÍNOV, 2017 [1929], p. 116), concordamos que todo e qualquer texto, seja ele verbal ou não-verbal, tem uma natureza social interativa, pois quem o produz tem uma intenção comunicativa. Como afirma Bakhtin (2006 [1979], p. 282), "A vontade discursiva do falante realiza-se antes de tudo na escolha de um certo gênero de discurso." (Grifos do autor). Assim, é se inserindo e se aprofundando em um projeto de investigação a respeito dos discursos humanos e da interação humana no processo de comunicação que surge(m) o(s) conceito(s) de dialogismo, para Bakhtin. De acordo com este teórico,

A orientação dialógica é naturalmente um fenômeno próprio a todo o discurso. Trata-se da orientação natural a qualquer discurso vivo. Em todos os seus caminhos até o objeto, em todas as direções, o discurso se encontra com o discurso de outrem e não pode deixar de participar, com ele, de uma interação viva e intensa. (BAKHTIN, 2010 [1934], p. 88)

Analisando o texto acima, percebemos que a língua, em seu vivenciamento, e em sua totalidade concreta, tem propriedade de ser dialógica. Dessa forma, quando reportamos nossa centralidade para o(s) sujeito(s) dialógico(s), percebemos que seus discursos só existem na forma de enunciações concretas, por serem constitutivamente os sujeitos do discurso. Para Santana,

Os enunciados concretos, como unidade real da comunicação, ocorrem a partir da alternância dos sujeitos dos discursos, isto porque o sujeito termina seu enunciado para passar a palavra ao outro, tornando-se um ser responsável e participativo pelo que enuncia, um agente produtor de sentidos dos discursos produzidos socialmente em situações concretas. (SANTANA, 2014, p. 2)

Dentro de uma perspectiva enunciativo-discursiva da linguagem, esta análise pretende compreender o Sermão expositivo a partir da abordagem dialógico-discursiva da linguagem, analisado sob a forma de diferentes esquemas sintático-semânticos de sua recepção/transmissão, e de propostas de atuação e circulação deste gênero discursivo. Procuramos observar as possibilidades de sentido presentes no Sermão, na busca de compreender como ocorre a apreensão das vozes sociais pelo sujeito e observando os efeitos discursivos a partir dos enunciados que se atualizam. Sob o viés do dialogismo, buscamos, assim, discorrer sobre o gênero em questão.

A pesquisa é de caráter bibliográfico e documental e o corpus constitui-se de 4 (quatro) versículos bíblicos relatados por Mateus em seu evangelho acerca de palavras do Cristo. O Sermão geralmente se realiza numa situação de comunicação específica em que o orador (ou expositor) une-se, pela interação verbal, ao(s) seu(s) destinatário(s). Dessa forma, o gênero citado se caracteriza pelas diferentes formas de presença do outro, ou seja, presença de diversas 
vozes sociais resultantes de interações interdiscursivas. Trata-se, portanto, a pesquisa, de uma produção de cunho qualitativo-interpretativo.

\title{
2 O ESTUDO DA ENUNCIAÇÃO E DO DISCURSO A PARTIR DE PERSPECTIVA ORAL DO USO DA LÍNGUA
}

Diversos estudiosos filiados às teorias textuais têm privilegiado o estudo da enunciação e do discurso a partir de perspectivas das mais variadas abordagens. Porém, quando nos reportamos, mesmo com um pequeno levantamento, às principais pesquisas disponíveis no Brasil sobre tal assunto, percebemos a precisão de mais visibilidade e atenção à temática, e isso se dá pela sua complexidade.

Para a reflexão sobre o conceito de enunciado, é necessário estabelecer diálogo com o texto de Volochínov citado "Estrutura do enunciado", cujo objetivo é apresentar os fundamentos de um horizonte dialógico de língua já presentes nele, bem como suas implicações para a análise de enunciados. O autor faz apontamentos sobre a orientação social do discurso e suas condições de produção e circulação em uma esfera social. Nesse vetor axiológico, é preciso atentar para o fato de que todo discurso é dialógico, todo discurso é direcionado a um interlocutor, segundo nos ensina Volochínov (2005 [1930], p. 4):

\begin{abstract}
Assim, todo enunciado (pronunciamento, conferência, etc.) é concebido em função de um ouvinte, isto é, da sua compreensão e da sua resposta - não sua resposta imediata, é claro, uma vez que não se deve interromper um orador ou um conferencista com observações pessoais; mas também em função do seu acordo ou seu desacordo, ou, em outras palavras, da percepção avaliativa do ouvinte; enfim, em função do "auditório do enunciado" (VOLOCHÍNOV, 2005 [1930], p. 4):
\end{abstract}

O fragmento supracitado permite a averiguação de que todo enunciado tem uma dimensão social inerente, ou seja, ele nasce e se desenvolve em uma realidade social, mundoconcreto-evento.

Uma segunda observação nos coloca mediante ao fato de que a maioria dos trabalhos preferenciam o uso de gêneros discursivos da escrita, conforme um pequeno censo realizado pelo professor FRANCELINO (2013, p. 9): “...Possenti (2002), Orlandi (1988, 1997, 2000, 2001a, 2001b), Gallo (1992), Gregolin (2001), Tfouni (2001, 2005), Magalhães (2003), Corcacini (1999), para citar alguns dos principais". Tendo em vista isso, o intuito deste trabalho é o de apresentar uma nova possibilidade de perspectiva autoral, observando como a mesma se estabelece em situações sociocomunicativas orais do uso da língua, como é o caso do gênero Sermão expositivo.

Para tanto, verifiquemos o que nos disponibiliza Lachler (1990, p. 15) acerca de como deve acontecer tanto a pesquisa quanto composição do sermão, para que se alcance uma exposição interativa:

I_PESQUISA

1_ Familiarização: percepções globais do parágrafo

2_ Exegese: no vernáculo e nos textos originais

3_ Estudo bíblico indutivo do texto

4_ Proposição Central 


\section{III_COMPOSIÇÃO}

1_ As divisões principais

2 _ As ilustrações (luzes)

3_ Conclusão (foco na decisão)

Introdução (o ouvinte é fisgado)

4_ Esboço do sermão (uma direção clara para todos)

Diante de tal método disposto pelo estudioso, observamos que esse processo lógico dos passos de pesquisa e composição para as mensagens expositivas é importantíssimo na construção semântica, pois este direcionamento impulsiona a ocorrência do dialogismo no gênero em questão. Na ótica de Lachler (1990, p. 18), "O importante é que a mensagem seja esboçada, levando-se em conta que os ouvintes não podem visualizá-la. O pregador-mestre (Efésios 4.11) deve estimular a imaginação do grupo com palavras vívidas a uma lógica fluente".

No momento em que o ouvinte é fisgado, significa que a atenção dele está filtrada naquilo que está sendo enunciado pelo pregador, as palavras não estão simplesmente flutuando, mas elas estão penetrando e atravessando o âmago dos interlocutores. Esse movimento discursivo ou deslocamento semântico [na construção do dialogismo cf. Bakhtin], na perspectiva de Frèdéric François (1994) é utilizado aqui para significar as ações dos interlocutores quanto à construção dos sentidos possíveis. O movimento de compreensão é o momento de interação entre pregador/ouvinte/sermão que partilham o dito e o não dito.

As interações no processo de exposição do Sermão revelam a importância de construir coletivamente o sentido da enunciação e de considerar os lugares e papéis ocupados pelos interlocutores no espaço eclesiástico. As práticas religiosas ou os modos de ler em Igreja ou outro lugar apropriado refletem não só a concepção de linguagem/leitura do pregador, mas também a relevância da interação expositor/ouvinte, expositor/Bíblia e ouvinte/Bíblia. Ao adotarmos, aqui, a perspectiva dialógica ou linguagem como interação, a atividade de leitura no ambiente proposto deverá pautar-se por essa concepção.

Ao considerarmos que os estudos linguísticos perpassam várias áreas do conhecimento, propomos, aqui, um Sermão pautado na proposta dialógica de Bakhtin e o círculo, que abordam a linguagem como interação entre os sujeitos marcada pela situação e meio social dos indivíduos. Nessa concepção, a linguagem é considerada interação constitutiva da identidade do sujeito e a leitura é um processo interativo de construção de sentido.

É imprescindível que todo pregador seja preparado, possua conhecimento teóricoteológico-bíblico e prático do que irá abordar no sermão e conheça também os aspectos histórico-biográficos dos autores com os quais manterá diálogo, as características de cada carta/obra, e saiba que esses elementos não podem ser dissociados do estudo do gênero escolhido, pois quando estão isolados não têm sentido completo e o ouvinte não compreenderá o texto como um todo, mas como algo fragmentado ou desprovido de significado.

Em sendo o sermão expositivo um dos diversos tipos de exposição oral, apreciemos o horizonte enunciativo de Texeira (et.al)

A exposição oral deve ser tratada como objeto de ensino de expressão oral... Em alguns casos a exposição vem de uma longa tradição e é constantemente praticada... Assim, a exposição permanece como uma atividade tradicional... Ao citar as características gerais do gênero pode-se dizer, segundo 
Dolz, Schneuwly et alli (2004), que a exposição é um discurso que se realiza numa situação de comunicação especifica chamada de "bipolar", unindo o orador ou expositor e seu auditório, assim, a exposição pode ser qualificada como um espaço-tempo de produção onde o enunciador vai ao encontro do destinatário, através de uma ação de linguagem que veicula um conteúdo referencial. Mas, se esses dois atores encontram-se reunidos nessa troca comunicativa particular que é a exposição, a assimetria de seus respectivos conhecimentos sobre o tema da exposição os separam: um representa o "especialista", o outro, se caracteriza como alguém disposto a aprender algo (Teixeira et al. 2008, p. 1-2).

As autoras elencam não apenas a importância de quem expõe, mas de quem ouve, pois ambos estão em contínuo processo de aprendizado(s) múltiplo(s) e heterogêneo(s). François (1984) mostra que a linguagem se constitui pela diversidade de modos de significar, e pelos movimentos constitutivos do discurso, o que robustece sua variabilidade semiológica.

Karl Lachler (1990, p. 26), ao retomar a importância da luz da oratória, afirma que “...Os pregadores brasileiros devem aprender a percorrer a todos os seus recursos culturais na tentativa de expor a Palavra de Deus". Ao elencar algumas categorias vantajosas (na ótica do autor) para a eficácia interativa do Sermão expositivo (idem, p. 55-57), Lachler nos disponibiliza três pontos fundamentais para que ocorra diálogo pleno entre o pregador e seus ouvintes: 1) A pregação expositiva ser baseada em livros da Bíblia; 2) Eleição de temas espontâneos, para que ocorra interação; 3) O fator da nutrição. Ater-nos-emos, aqui, apenas na terceira categoria, ou o fator da Nutrição.

O fator da Nutrição é a terceira vantagem da pregação expositiva. A palavra de Deus é alimento para a alma, mente e espírito. Na pregação expositiva, o pregador não tem de impor categorias "evangelísticas" ou "de edificação" ao seu sermão. A Palavra de Deus destina-se a ser todas as coisas para toda a humanidade. Ela traz o novo nascimento a alguns e concede edificação moral a outros, segundo o desejo do Espírito (LACHLER, 1990, p. 55)

Esse Nutrir, dentro da perspectiva bakhtiniana, seria o dialogismo, interação viva entre duas consciências. A Palavra de Deus destina-se a ser todas as coisas para toda a bumanidade. Interessante que Bakhtin nos dirá que, acerca da metodologia das ciências humanas, há dois limites existentes, um é o conhecimento da coisa (morta) - quando eu me volto para mim mesmo [monologismo] e outro o conhecimento do indivíduo, enquanto objeto prático e vivo [quando eu me volto para o outro, dialogismo]. Esse segundo limite é "a ideia de Deus em presença de Deus, o diálogo, a interrogação, a prece” (Bakhtin, 2006 [1979], p. 394).

Ao centralizarmo-nos na construção textual anteriormente apresentada, vemos que há uma proposta, por parte do autor, de que o sermão seja externado e produzido de forma a alcançar a todos, a voz tem de ser clara, estar entre o objetivo e o subjetivo, deve haver um escorrimento semântico entre a teoria e a prática, para que os ouvintes compreendam tudo o que está sendo exposto pelo pregador.

Quanto à clareza enunciativa, como categoria essencial para a construção do sentido, observemos o que nos traz Silva (1992, p. 83):

O pregador, mais que qualquer outra pessoa, tem a sagrada obrigação de usar linguagem muito clara. Isso é de suma importância, quando se expressa uma lei, quando se escreve um título de propriedade ou coisas assim. Com efeito, tem maior importância ainda na proclamação da Palavra de Deus. Os 
escribas responsáveis pelo ensino divino no Antigo Testamento eram homens dotados de grande saber. Entretanto, exigia-se deles que, ao ministrar seus ensinamentos, fossem claros e objetivos. "E leram no livro, na lei de Deus; e declarando, e explicando o sentido, faziam que, lendo, se entendesse" (Ne 8.8).

Percebamos que o entender, o compreender, é uma Palavra chave na construção do sentido, e isso é perspectiva dialógica. Acerca desse contato entre sujeitos no processo de interação, nos dirá Mikhail Bakhtin (2011, p. 395/396): “...o ser da expressão é bilateral: só se realiza na interação entre duas consciências (a do eu e a do outro); é o campo de encontro entre duas consciências, a zona do contato interior entre elas."

Na percursividade dialógica, então, cada elemento do sermão (a obra) é explanado aos ouvintes na resposta que o autor lhes dá (uma resposta à resposta). Nessa direcionalidade, o autor do sermão acentua cada particularidade de sua enunciação, seus traços permeáveis, os atravessamentos discursivos, e cada ato vivo. O sermão funciona como uma exposição responsivo-ativa em que o autor responde axiologicamente ao seu auditório, ele se responsabiliza por todo o enunciado que está sendo replicado. Percebemos, então, um jogo semântico-cênico: o sermão expositivo está servindo de resposta tanto ao enunciado que permite a enunciação quanto às pessoas que o recebem - escuta dialógica.

\section{JESUS E SEU SERMÃO SOBRE O SAL DA TERRA E A LUZ DO MUNDO}

Para a análise, delimitamos o sermão de Jesus sobre o sal da terra e a luz do mundo, em que entendemos se tratar de uma seleção/combinação lexical enunciativa realizada pelo enunciador. Vejamos, primeiramente, o contexto em que se encontrava Jesus Cristo, no momento em que começou a expor, oralmente, seu discurso sobre o sal da terra e a luz do mundo. De acordo com o capítulo 5 do Evangelho segundo Mateus, vendo a multidão, Jesus subiu a um monte, e, assentando-se, aproximaram-se dele seus discípulos (v. 1). Após ensinar várias coisas sobre as beatitudes (dos versículos 2 ao 12), Jesus adentra ao discurso sobre o sal da terra e a luz do mundo. Então, conta-nos o escrito que Cristo começou a pronunciar para seus discípulos:

V. 13: Vós sois o sal da terra; e se o sal for insípido, com que se há de salgar? Para nada mais presta senão para se lançar fora, e ser pisado pelos homens.

V. 14: Vós sois a luz do mundo: não se pode esconder uma cidade edificada sobre um monte.

A partir do contexto acima, percebemos que o princípio da seleção lexical é manifestado pelo sujeito falante Jesus Cristo, a partir do momento em que seleciona uma combinação de palavras da língua em que enuncia. Essa escolha seletiva se dá em função de diversos aspectos, dentre os quais podemos salientar, por exemplo, as condições amplas e imediatas da enunciação. 1 - As condições amplas e imediatas da enunciação. Em outras palavras, para que(m) eu falo, com que intuito eu falo, que papel(is) social(is) desempenha(m) meu(s) interlocutor(es) no processo enunciativo e o gênero discursivo nos quais se integram as interações.

No caso do sujeito enunciativo Jesus Cristo, ele precisou estar de acordo com as condições emergentes do seu discurso. Como falaria? De que forma pregaria seu Sermão, se só havia os 
discípulos com ele? Caso seja feita uma leitura mais profunda não só destes versículos, mas também dos circundantes, veremos que a enunciação discursiva é falada (por Jesus) unicamente aos seus discípulos, de acordo com Mt 5. 1, pois apenas eles se aproximaram do mestre. Isso muda totalmente o percurso interpretativo, pois nos permite entender o porquê de Jesus lhes poder falar metáforas profundas:

Mt. 13, 10: E, acercando-se dele os discípulos, disseram-lhe: Por que lhes falas por parábolas?

V 11: Ele, respondendo, disse-lhes: Porque a vós é dado conhecer o mistério do reino dos céus, mas a eles não lhes é dado;

V 13: Por isso lhes falo por parábolas; Porque eles, vendo, não veem e, ouvindo, não ouvem nem compreendem.

Neste instante, o sujeito falante teve o intuito de selecionar seu discurso de forma metafórica e profunda porque sabia que a maior parte dos discípulos o compreenderia, e estaria preparada para interpretá-lo e principalmente cumpri-lo. Com isso, entendemos que existe um querer-dizer por parte do enunciador, e ao mesmo tempo um querer-ocultar através de seu dizer. Neste momento em que Jesus enunciou sua parábola, vários enunciados ficaram permeáveis à sua expressividade, ou seja, seu discurso poderia ter mais de um sentido ou significado [a depender de como foi recebido por cada destinatário - o(s) outro(s)]. Conforme Bakhtin (2006 [1979], p. 318),

[...] em todo enunciado, contanto que o examinemos com apuro, levando em conta as condições concretas da comunicação verbal, descobriremos as palavras do outro ocultas, ou semi-ocultas e com graus diferentes de alteridade. Dir-se-ia que um enunciado é sulcado pela ressonância longínqua e quase inaudível da alternância dos sujeitos falantes e pelos matizes dialógicos, pelas fronteiras extremamente tênues entre os enunciados e totalmente permeáveis à expressividade do autor. (BAKTHIN, 2006 [1979]. p. 318.)

Como confirmaremos mais à frente, a dialogicidade deste discurso ocorre na própria enunciação, pois o discurso estava sendo comum a todos os discípulos. Perceba-se, também, que ocorre sempre uma explicação posterior, à proporção que cada metáfora é realizada, o que selecionamos aqui como o segundo momento de cada enunciação. O primeiro momento consiste na exposição das metáforas, e o segundo, na explicação ou contextualização de cada uma delas. Quando adentramos, portanto, neste segundo instante dos enunciados de Cristo, entendemos que o discurso se estabelece dialogicamente com todos os que se posicionam axiologicamente a compreender as metáforas.

Demonstremos isso:

Quadro 1: Enunciações do sujeito Jesus Cristo 


\begin{tabular}{|l|l|}
\hline \multicolumn{1}{|c|}{$\begin{array}{c}\text { Primeiro momento do discurso de } \\
\text { Jesus } \\
\text { [Exposição] }\end{array}$} & $\begin{array}{l}\text { Segundo momento do discurso de Jesus } \\
\text { [Explicação ou contextualização] }\end{array}$ \\
\hline $\begin{array}{l}\text { Versículo 13 (parte a): Vós sois o sal da } \\
\text { terra. }\end{array}$ & $\begin{array}{l}\text { Versículo 13 (parte b): E se o sal for } \\
\text { insípido, com que há de salgar? Para nada } \\
\text { mais presta, senão para se lançar fora, e } \\
\text { ser pisado pelos homens. }\end{array}$ \\
\hline $\begin{array}{l}\text { Versículo 14 (parte a): Vós sois a luz do } \\
\text { mundo. }\end{array}$ & $\begin{array}{l}\text { Versículos 14 (parte b): Não se pode } \\
\text { esconder uma cidade edificada sobre um } \\
\text { monte. } \\
\text { Versículo 15: Nem se acende a candeia e } \\
\text { se coloca debaixo do alqueire, mas no } \\
\text { velador, e dá luz a todos os que estão na } \\
\text { casa. } \\
\text { Versículo 16: Assim resplandeça a vossa } \\
\text { luz diante dos homens, para que vejam as } \\
\text { vossas obras e glorifíquem ao vosso Pai, } \\
\text { que está nos céus. }\end{array}$ \\
\hline
\end{tabular}

Fonte: dados do autor

Ao analisarmos o quadro, podemos entender que, ao (a)firmar os discípulos como o sal da terra, Jesus os identifica como seres de sublime importância na divulgação de seu evangelho, dos quais depende o bom gosto, o "salgar", e os benefícios para que o alimento da terra (o pão, que é o próprio Jesus Cristo, de acordo com João 6. 35) seja bom, perfeito e agradável.

Este enunciado mantém diálogo pleno com o que é contextualizado na carta de Paulo aos Colossenses, quando este último exorta o povo à oração e sabedoria: "A vossa palavra seja sempre agradável, temperada com sal, para que saibais como convém responder a cada um." (Col. 4. 6) (Grifos nossos). De igual maneira Jesus alerta seus discípulos, afirmando que se não assumirem a função do sal, para nada mais prestarão, senão para serem lançados fora do ministério, e serem pisados pelos homens, já que o mundo não os aceitará. Desta forma, na contextualização desta passagem, quando a linguagem se torna comum a todos, dá-se o princípio dialógico.

$\mathrm{Na}$ concepção dialógica de linguagem, o ensino deve respaldar-se na interação e dinamismo, a Igreja ou o pátio (ou até uma casa anexa) passam a ser o espaço onde ocorrem a interação e o diálogo para a construção do sentido do gênero discursivo e destacam-se os movimentos semânticos entre os interlocutores, os quais resultam em ações de interpretação, compreensão, análise linguística, avaliação. $O$ Sermão não constitui um amontoado de informações, mas uma construção de sentidos proveniente da interação ou da mediação do pregador e ouvintes nas atividades desenvolvidas no ambiente eclesial.

Propomos trabalhar com o gênero Sermão Expositivo e as ações que são planejadas pelo pregador para que a exposição seja mais interativa e o interlocutor participante ativo de sua aprendizagem e da construção do conhecimento, a partir das relações interpessoais que ocorrem no ambiente mais apropriado.

\section{CONCEPÇÃO DIALÓGICA DA LINGUAGEM: O AUTOR/PREGADOR E SEU SERMÃO}


A concepção dialógica de linguagem defende que, antes mesmo de falar, “(...) o locutor altera, 'modula' sua fala, seu modo de dizer, de acordo com a imagem presumida que cria de interlocutores típicos, ou seja, representativos, do grupo a que se dirige." (Sobral, 2009, p.39).

Nesta linha interpretativa, segundo Sobral (2009, p. 51), o sujeito, dentre outras características que o constituem, é aquele que

Age sempre (o que inclui todos os seus atos: cognitivos, verbais etc.) segundo uma avaliação/ valoração daquilo que faz ao agir/falar, e pela qual se responsabiliza, e o faz a partir tanto da identidade que forma e vê reconhecida como das coerções que suas relações sociais lhe impõem ao longo da vida e que vão alterando essa identidade que ele veio a formar. (SOBRAL, 2009, p. 51).

Nesta direcionalidade, tem-se que a significação da palavra, assim como os seus sentidos, está sendo preservada no processo de utilização coletiva. Através do Sermão expositivo, está havendo troca de conhecimentos, interação. De acordo com a Teoria Dialógica do Discurso, todos os enunciados no processo de comunicação são dialógicos, logo, para o pregador, em sua enunciação, existe uma dialogização interna da palavra, que é repassada pela palavra - o silêncio, a resposta - do outro (os ouvintes).

De acordo com as propostas teórico-filosóficas de Bakhtin e o Círculo, todos os enunciados no processo de comunicação são dialógicos, logo não seria diferente com o discurso de Jesus, na modalidade sermão. Em seu discurso sobre "o sal da terra e a luz do mundo" existe uma dialogização interna da palavra, que é perpassada pela palavra do outro (a multidão). A respeito disso afirma Fiorin (2006, p. 19) que “...o enunciador, para constituir um discurso, leva em conta o discurso de outrem, que está presente no seu. Por isso, todo o discurso é inevitavelmente ocupado, atravessado, pelo discurso alheio. O dialogismo são as relações de sentido que se estabelecem entre dois enunciados".

O pregador, como enunciador do sermão expositivo, para constituir seu discurso, leva em conta o discurso de outrem, utilizando-o no seu. Avalia todas as condições necessárias para que ocorra compreensão entre os interlocutores. Essa nova enunciação confere caráter de valoração para a vivência da sabedoria - construção do conhecimento, em que há uma reação responsiva e responsável dos interlocutores para com outros discursos, naquele contexto sócio-histórico.

Quando falamos, por exemplo, que há uma "relação arquitetonicamente estável e dinamicamente viva" (Bakhtin, 2006 [1979], p.3) do autor com a personagem, ou com a obra de arte, ou ainda com quaisquer textos que estejam sob seu horizonte, significa que é exatamente este autor, o pregador do sermão, quem atribui os múltiplos sentidos à sua exposição. A mensagem que está sendo enunciada deve ser compreendida pelo auditório tanto em seu fundamento geral e de princípio quanto nas peculiaridades individuais.

Um sermão expositivo é aquele que toma o ponto principal de uma passagem da Escritura Sagrada (no caso, a Bíblia) e o reveste interdiscursivamente, tornando-o o ponto principal do sermão e o aplica à contemporaneidade da própria produção discursiva. Em outras palavras, o sermão expositivo é constituído pelos efeitos atribuídos pelo autor, em que este expõe uma escritura, seus diversos sentidos, e os molda, exibindo sua relevância para a vida dos ouvintes.

No caso do sermão expositivo, o escopo enunciativo que está servindo de direcionamento para o pregador/expositor pode ser uma porção mais ou menos extensa da Bíblia —um capítulo inteiro ou mais — e as divisões provêm da passagem, como no caso do sujeito Jesus Cristo, que 
reportava-se à Lei Mosaica para fundamentar algumas ordenanças da Graça. Este condiciona o pregador a extrair todas as subdivisões, bem como as divisões principais, da mesma unidade bíblica que pretende expor, e esta confere a arquitetônica discursiva, o todo, com seus entornos.

Bakhtin apresenta uma riquíssima construção acerca da Compreensão que ocorre entre os interlocutores, no decorrer do dialogismo:

A compreensão. Desmembramento da compreensão em atos particulares. Na compreensão efetiva, real e concreta, esses atos se fundem indissoluvelmente em um único e mesmo processo de compreensão, porém cada ato particular tem uma autonomia ideal semântica (de conteúdo) ideal e pode ser destacado do ato empírico concreto. 1) A percepção psicofisiológica do signo físico (palavra, cor, forma espacial). 2) $\mathrm{O}$ reconhecimento do signo (como algo conhecido ou desconhecido); a compreensão de seu significado reprodutível (geral) na língua. 3) A compreensão de seu significado em dado contexto (mais próximo ou mais distante). 4) A compreensão ativodialógica (discussão-discordância); A inserção no contexto dialógico. O elemento valorativo na compreensão e seu grau de profundidade e de universalidade. (BAKHTIN, 2006 [1979], p. 398).

Desta maneira, o sermão consiste na exposição de certo enunciado religioso, e a passagem converte-se no tecido do discurso. Em outras palavras, o corpo ético-cognitivo (pensamentos que são abarcados pelo nível estético) provém diretamente do enunciado, e o sermão passa a ser, definitivamente, compreendido responsivo-ativamente. Quando assim se faz, o sermão enunciativo é tratado expositivamente, e o discurso todo torna-se uma explanação clara e objetiva do enunciado.

\section{CONCLUSÃO}

O filósofo russo Mikhail Bakhtin afirma que a compreensão responsiva de um todo verbal é sempre dialógica. A compreensão do todo do enunciado e da relação interativa, por exemplo, entre pregador e ouvintes, é necessariamente dialógica (é também o caso do pesquisador nas ciências humanas); aquele que pratica ato de compreensão passa a ser participante do diálogo, ainda que seja num nivel especifico $\mathrm{O}$ observador/contemplador não se situa em parte alguma fora do mundo observado.

Sua observação é parte integrante do objeto observado. Uma vez que a fala do emissor é externada e saturada de enunciação, o discurso sobre o sal da terra e a luz do mundo é reacentuado por Jesus Cristo no contato que estabelece com a realidade sócio-históricoideológica dos interlocutores que o recebem.

Assim, a compreensão responsivo-ativa do auditório se dá porque Jesus projeta a si e ao sermão responsável e responsivamente pelo seu discurso, configurando-se e constituindo-se dialogicamente. Conforme se demonstra, compreendemos como se manifesta a dialogicidade do sermão de Jesus a partir do instante em que a (arena) torna-se ambiente de múltiplas vozes. O expositor demonstra deslocamentos colaborativos em relação aos seus interlocutores, e dessa forma seu sermão é projetado sob prisma da dialogia, caracterizado pela forte tensão entre suas palavras e o dizer (o silêncio é uma forma de dizer algo) do outro.

Por fim, podemos perceber o quanto o trabalho com a linguagem, considerada como interação entre sujeitos determinados social e historicamente, revela o modo como a Igreja se tornou um espaço favorecido à interação verbal e à construção do conhecimento partilhado 
entre o pregador e seus ouvintes. Essa proposta para uma pregação expositiva, como já afirmamos anteriormente, pauta-se na concepção dialógica bakhtiniana de linguagem e afirma que o ato de compreender é um processo que envolve várias vozes. Assim, não há um lugar determinado nem um papel fixo para o sujeito, sobretudo no espaço e tempo do Sermão Expositivo, onde as relações interpessoais tornaram-se um componente relevante para o ensino e aprendizagem. Desse ponto de vista, as enunciações dos pregadores tornam-se um ato de prazer e a leitura acompanhada (da Bíblia) um acréscimo à experiência dos leitores/ouvintes competentes. Portanto, sugerimos o ensino do sermão com base nos pressupostos de estudos bakhtinianos.

\section{REFERÊNCIAS BIBLIOGRÁFICAS}

BAKHTIN, Mikhail M. 2006 [1979]. Estética da Criação Verbal / prefácio à edição francesa Tzvetan Todorov; introdução e tradução do russo Paulo Bezerra. - 4. ed.- São Paulo: Editora WMF Martins Fontes. 476 p.

2010 [1934]. Questões de Literatura e de Estética - a teoria do romance. Equipe de tradução: Bernardini; Júnior; Nazário; Júnior; Andrade. - 6. ed. ed. - São Paulo: Hucitec Editora. 439 p.

BÍBLIA SAGRADA. 2012. Antigo e Novo Testamento. Português. Belo Horizonte: Editora Atos. 1988 p.

FIORIN, J. L. 2006. Introdução ao pensamento de Bakbtin. — São Paulo: Ática. 144 p.

FRANCELINO, P. F. (Org). 2013. Teoria dialógica do discurso - exercícios de reflexão de análise. João Pessoa: editora da UFPB. 153 p.

FRANÇOIS, F. 1994. Morale et mise en mots. Paris: L'Harmattan. 213 p.

1996. Práticas do oral: diálogo, jogo e variações das figuras do sentido. Trad: Lélia E. Melo Carapicuíba, São Paulo. Pró-fono, Departamento editorial. 188 p.

LACHLER, K. 1990. Prega a Palavra - passos para a pregação expositiva. Tradução - Robinson Malkomes. São Paulo: Vida Nova. 131 p.

SANTANA, W. K. F. 2014. A autoria e a responsividade linguistica e discursiva de jesus cristo em sua exposição acerca do sal da terra e da luz do mundo, a partir do evangelho segundo Mateus. A literatura \& tempo: cem anos de encantamento - IN: ARAGAO. Maria do Socorro Silva de. (Org.). II Congresso Nacional de Literatura - II CONALI - Anais. João Pessoa: Mídia. p. 1042-1054.

SILVA, S. P. 1992. Homilética - o Pregador e o Sermão. $1^{a}$ ed. Rio de Janeiro: Casa publicadora das Assembleias de Deus. 112 p.

SOBRAL, A. 2009. Do dialogismo ao gênero: as bases do pensamento do círculo de Bakhtin. Campinas, SP: Mercado das Letras. 175 p.

TEXEIRA, A. T; BLASQUE, et al. 2008. A exposição oral na sala de aula. In: VII Seminário De Pesquisa Em Ciências Humanas. Anais. UEL. Organização de Mirian Donat e Rogério Ivano Londrina: Eduel. dez. p. 1-9.

VOLOCHÍNOV, Valentin Nikolaevich. (círculo de Bakhtin). Marxismo e filosofia da linguagem Problemas fundamentais do método sociológico na ciência da linguagem. Tradução de Sheila 
Grillo e Ekaterina Vólkova Américo - Ensaio introdutório de Sheila Grillo. $1^{\mathrm{a}}$ ed. São Paulo: Editora 34, 2017 [1929].

. 1976 [1926]. Discurso na vida e na arte: sobre a poética sociológica. Trad. de Carlos Alberto Faraco e Cristóvão Tezza da edição inglesa de TITUNIK, I. R. "Discourse in life and discourse in art - concerning sociological poetics". In: VOLOCHINOV, V. N. Freudism. New York: Academic Press. 110 p.

Estrutura do enunciado. Tradução de Ana Vaz, para fins didáticos. 1930, com base na tradução francesa de Tzevan Todorov ("La structure de l'énoncé, 1930). In: TODOROV, T. Mikhail Bakbtine: le principe dialogique. Paris: Seuil, 2005. p. 287-316.

Recebido em: 05/06/2018

Aprovado em: 23/07/2018

Publicado em: 31/12/2018 